\title{
Mouse model of enlarged vestibular aqueducts defines temporal requirement of S/c26a4 expression for hearing acquisition
}

\author{
Byung Yoon Choi, ${ }^{1}$ Hyoung-Mi Kim, ${ }^{2}$ Taku Ito, ${ }^{3}$ Kyu-Yup Lee, ${ }^{3}$ Xiangming Li, ${ }^{2}$ Kelly Monahan, ${ }^{3}$ \\ Yaqing Wen, ${ }^{3}$ Elizabeth Wilson, ${ }^{1}$ Kiyoto Kurima, ${ }^{3}$ Thomas L. Saunders, ${ }^{4}$ Ronald S. Petralia, ${ }^{5}$ \\ Philine Wangemann, ${ }^{2}$ Thomas B. Friedman, ${ }^{1}$ and Andrew J. Griffith ${ }^{3}$
}

\begin{abstract}
${ }^{1}$ Laboratory of Molecular Genetics, National Institute on Deafness and Other Communication Disorders, NIH, Rockville, Maryland, USA
${ }^{2}$ Anatomy and Physiology Department, Kansas State University, Manhattan, Kansas, USA. ${ }^{3}$ Otolaryngology Branch,

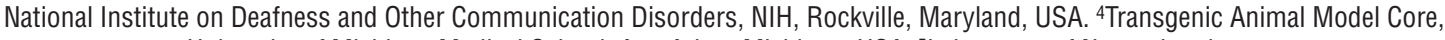
University of Michigan Medical School, Ann Arbor, Michigan, USA. ${ }^{5}$ Laboratory of Neurochemistry, National Institute on Deafness and Other Communication Disorders, NIH, Bethesda, Maryland, USA.
\end{abstract}

\begin{abstract}
Mutations in human SLC26A4 are a common cause of hearing loss associated with enlarged vestibular aqueducts (EVA). SLC26A4 encodes pendrin, an anion-base exchanger expressed in inner ear epithelial cells that secretes $\mathrm{HCO}_{3}{ }^{-}$into endolymph. Studies of Slc26a4-null mice indicate that pendrin is essential for inner ear development, but have not revealed whether pendrin is specifically necessary for homeostasis. Slc26a4-null mice are profoundly deaf, with severe inner ear malformations and degenerative changes that do not model the less severe human phenotype. Here, we describe studies in which we generated a binary transgenic mouse line in which Slc26a4 expression could be induced with doxycycline. The transgenes were crossed onto the Slc26a4-null background so that all functional pendrin was derived from the transgenes. Varying the temporal expression of Slc26a4 revealed that E16.5 to P2 was the critical interval in which pendrin was required for acquisition of normal hearing. Lack of pendrin during this period led to endolymphatic acidification, loss of the endocochlear potential, and failure to acquire normal hearing. Doxycycline initiation at E18.5 or discontinuation at E17.5 resulted in partial hearing loss approximating the human EVA auditory phenotype. These data collectively provide mechanistic insight into hearing loss caused by SLC26A4 mutations and establish a model for further studies of EVA-associated hearing loss.
\end{abstract}

\section{Introduction}

Enlargement of the vestibular aqueduct (EVA; OMIM 600791) is commonly observed in temporal bones of children with sensorineural hearing loss (1). The corresponding soft tissue abnormality is enlargement of the endolymphatic duct and sac (2), nonsensory epithelial organs whose primary function is thought to be ionic and osmotic regulation of endolymph. Hearing loss associated with EVA is predominantly sensorineural, variable in severity, and asymmetric or unilateral, with an onset in the first few years of life (3). EVA may be the sole radiologic abnormality or it may be associated with cochlear anomalies such as a reduced number of turns with an incomplete osseous partition. There does not appear to be an association of the presence of a cochlear anomaly with severity of hearing loss when other underlying genotypic and phenotypic correlations are accounted for in ears with EVA (4). Moreover, there is no correlation of the degree of enlargement of the vestibular aqueduct with degree of hearing loss in ears meeting typical diagnostic criteria for $\operatorname{EVA}(3,4)$. Therefore, these gross morphogenetic anomalies are not the direct cause of hearing loss in EVA.

Hearing loss with EVA may be an isolated clinical finding or it may be associated with abnormalities of other organs as part of a syndrome. The most common syndrome associated with EVA is

Authorship note: Byung Yoon Choi, Hyoung-Mi Kim, and Taku Ito contributed equally to this work.

Conflict of interest: The authors have declared that no conflict of interest exists. Citation for this article: J Clin Invest. 2011;121(11):4516-4525. doi:10.1172/JCI59353.
Pendred syndrome (OMIM 274600), an autosomal recessive disorder originally reported to comprise thyroid goiter and sensorineural hearing loss (5). Pendred syndrome is caused by mutations in the SLC26A4 gene (formerly called PDS; OMIM 605646) (6), which can also be identified in many cases of nonsyndromic EVA (7-11). Although goiter is incompletely penetrant, EVA is a highly penetrant manifestation of 2 mutant alleles of $\operatorname{SLC} 26 A 4(2,10,12)$.

SLC26A4 encodes a multipass transmembrane protein called pendrin (6). In the mouse inner ear, pendrin functions as an exchanger of $\mathrm{Cl}^{-}$and $\mathrm{HCO}_{3}{ }^{-}$(13). It is expressed in nonsensory epithelial cells of the outer sulcus and spiral prominence of the cochlear duct, transitional cells surrounding the vestibular neuroepithelia, and mitochondria-rich cells of the endolymphatic sac (refs. 14-16 and Figure 1). These cells are thought to contribute to $\mathrm{pH}$ and ionic homeostasis of endolymph, which is the potassiumrich fluid filling the scala media of the cochlear duct. Endolymph bathes the apical mechanosensory stereocilia bundles of hair cells, and maintenance of its distinctive ionic composition and $\mathrm{pH}$ is necessary for auditory function (17). Pendrin is first expressed at E11.5 in the mouse endolymphatic sac and at E13.5 to E16.5 in the cochlea, utricle, and saccule (18).

An Slc26a4 ${ }^{\Delta}$ knockout mouse allele was generated by targeted deletion of exon 8 of Slc26a4 (19). Slc26a4 $4^{\Delta / \Delta}$ mice have vestibular dysfunction, profound hearing loss, and massively enlarged endolymphatic spaces throughout the entire inner ear (19). Enlargement of the endolymphatic sac and cochlea begins at E14.5, with cochlear endolymph acidification evident at E15.5, developmental 
A
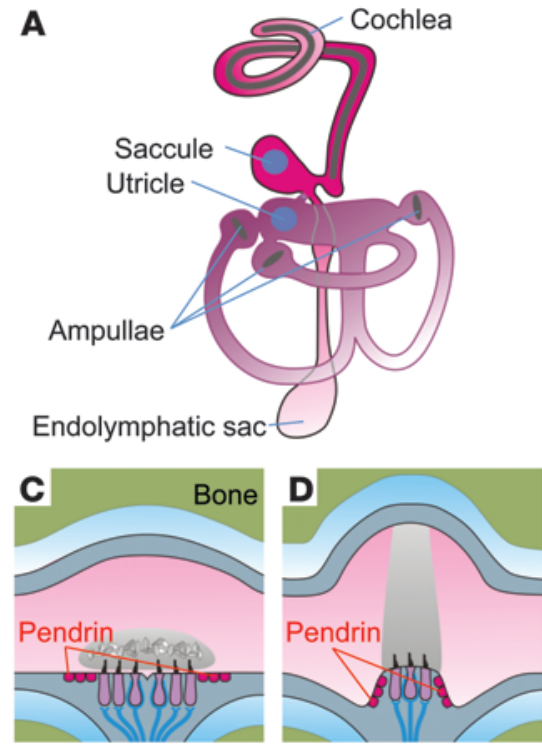
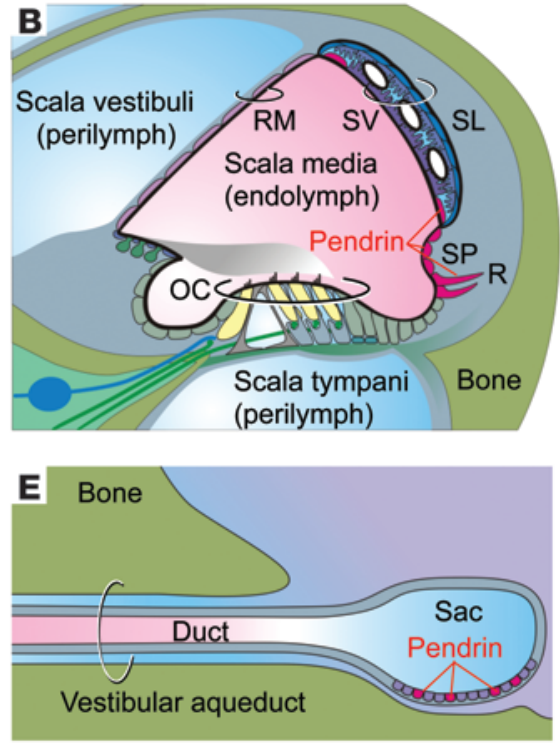

Figure 1

Pendrin expression in the inner ear. (A) Overview of the inner ear. The mammalian inner ear consists of the cochlea, which is the organ for hearing, the vestibular labyrinth, which is the organ for detecting linear acceleration in the saccule and utricle, and angular acceleration along 3 spatial axes in the ampullae. The membranous labyrinth (shown) is encapsulated in bone (not shown). (B) Cross-section of 1 turn of the cochlea. The cochlea consists of an epithelia-lined duct that is filled with endolymph. This duct is surrounded by 2 open fluid compartments that are filled with perilymph. The main structures of the cochlear duct are the stria vascularis (SV), Reissner membrane (RM), and the organ of Corti (OC). The stria vascularis generates the EP and secretes $\mathrm{K}^{+}$into endolymph. The organ of Corti contains the sensory hair cells. Pendrin is expressed in epithelial cells of the spiral prominence (SP), in root cells (R), and in spindle cells of the stria vascularis. Cross sections are shown for the saccule or utricle (C), an ampulla (D), and the endolymphatic duct and sac (E). The saccule, utricle, ampullae, and endolymphatic duct are epithelia-lined structures that are filled with endolymph and surrounded by perilymph. The endolymphatic sac is surrounded by cerebrospinal fluid. Pendrin is expressed in nonsensory epithelial cells surrounding the sensory hair-cell patches in the saccule, utricle, and ampulla. In addition, pendrin is prominently expressed in the endolymphatic sac.

retardation of the stria vascularis at $\mathrm{P} 3$, loss of the endocochlear potential (EP) at P10, degeneration of hair cells as early as P15, and failure to acquire hearing between P12 and P15 (13, 16, 18-20).

Given the severe developmental abnormalities of Slc26a4 $4^{\Delta / \Delta}$ ears, it remains unknown whether pendrin is also required for homeostatic function of the mature inner ear. This question is relevant to strategies to prevent or retard progressive hearing loss in EVA. Moreover, the profound hearing loss and inner ear malformations in the Slc26a $44^{\Delta / \Delta}$ mouse do not model the less severe phenotypes frequently observed in human EVA patients (3, 4, 9, $10)$. We thus generated a mouse line in which we could reversibly activate and deactivate Slc26a4 expression to define the temporal requirements for pendrin in the auditory system and to model human EVA phenotypes.

\section{Results}

Transgenic mice with doxycycline-inducible expression of Slc26a4. A binary transgenic mouse line was generated in which all Slc26a4 expression is inducible with doxycycline (dox) (reviewed in ref. 21). The effector transgene $(\mathrm{Tg}[\mathrm{E}])$ expresses reverse tetracycline-controlled transactivator (rtTA) under the control of the mouse Slc26a4 promoter and cis-regulatory elements (Figure 2). The responder transgene $(\mathrm{Tg}[\mathrm{R}]$ ) expresses a full-length Slc26a4 cDNA under bidirectional control of the tetracycline operator. In the presence of dox, within the temporal and spatial expression domain of Slc26a4 regulatory elements, rtTA binds to the tetracycline operator to activate expression of Slc26a4 cDNA. The transgenic lines were crossed onto the Slc26a4 $4 / \Delta$ background so that the responder transgene is the only source of functional pendrin. We generated and characterized 2 founder lines for $\mathrm{Tg}[\mathrm{E}]$ and 5 lines for $\mathrm{Tg}[\mathrm{R}]$ to identify combinations of $\mathrm{Tg}[\mathrm{E}]$ and $\mathrm{Tg}[\mathrm{R}]$ lines with Slc26a4 expression that were inducible only in the presence of dox.

We identified a single combination of $\operatorname{Tg}[\mathrm{E}]$ and $\operatorname{Tg}[\mathrm{R}]$ lines with inducible and tight expression of Slc26a4. Figure 3 shows the results of anti-pendrin immunostaining of the cochlea and endolymphatic sac of $\operatorname{Tg}[\mathrm{E}] ; \mathrm{Tg}[\mathrm{R}] ;$ Slc26a4 $4^{\Delta / \Delta}$ mice at 1 month of age. We were able to detect strong pendrin immunoreactivity in $\operatorname{Tg}[\mathrm{E}] ; \operatorname{Tg}[\mathrm{R}] ; 3 \operatorname{lc} 26 \mathrm{~A}^{\Delta / \Delta}$ ears when dox was initiated at E0 (IEO: dox initiated at E0 and administered for entire lifespan), although the level of staining in the endolymphatic sac was less than in Slc26a4 ${ }^{/ /+}$controls (Figure 3). There was no detectable immunoreactivity at 1 month of age when dox was discontinued at E17.5 (DE17.5; Figure 3). These results demonstrate inducible expression of pendrin protein from $\operatorname{Tg}[\mathrm{E}]$ and $\operatorname{Tg}[\mathrm{R}]$ and low or no pendrin expression in the absence of dox.

Temporal requirements of auditory function for Slc26a4 expression. To define the temporal requirements of Slc26a4 expression for cochlear function, the time point of dox initiation (I) was varied between $\mathrm{E} 0$ and $\mathrm{P} 6$. The auditory brainstem response (ABR) thresholds were measured at P25-P35, and the EP and endolymphatic and perilymphatic $\mathrm{pH}$ were measured at P25-P56. Since Slc26a4 expression is strongly and rapidly induced within the first few hours of initiation of dox (not shown), the onset of dox administration approximates the onset of Slc26a4 expression.

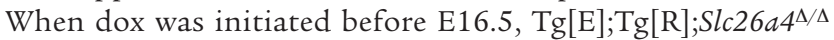
mice had ABR thresholds within the range (40-50 decibels sound pressure level [dB SPL]) of normal-hearing Slc26a $4^{\Delta /+}$ controls (Figure 4A). When dox was initiated at E16.5, ABR thresholds were still within the range (40-50 dB SPL) of normal-hearing Slc26a $4^{\mathrm{A} /+}$ controls (Figure 4A), but the EP and the endolymphatic $\mathrm{pH}$ were reduced compared with controls (Figure 5, A and B). When dox initiation was delayed until E18.5, there were large elevations of hearing thresholds with mean ABR thresholds of approximately $110 \mathrm{~dB}$ SPL in worse-hearing ears and $95 \mathrm{~dB}$ SPL in better-hearing ears, which are indicative of severe hearing loss (Figure 4A). These were associated with severe reductions in the EP from approximately $90 \mathrm{mV}$ to $10 \mathrm{mV}$ (Figure 5A). The endolymphatic $\mathrm{pH}$ was reduced from approximately 7.5 to 7.1 (Figure $5 \mathrm{~B}$ ). These values are similar to those reported in Slc26a4 $4^{\Delta / \Delta}$ mice (13). Further delay of initiation of dox until P2 led to even higher ABR thresholds that were indistinguishable from those of Slc26a $4^{\Delta / \Delta}$ controls (Figure 4A). 

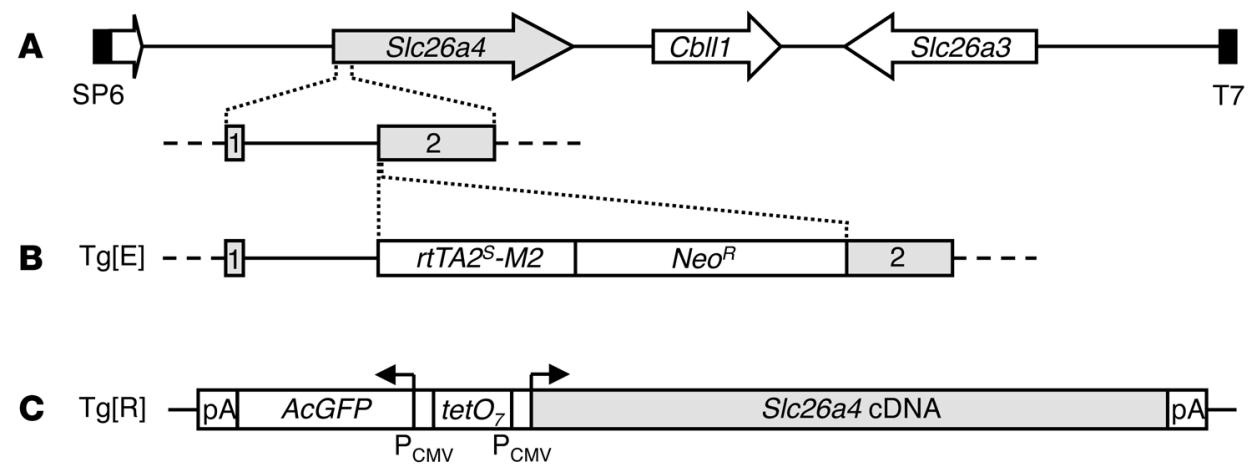

Figure 2

$\mathrm{Tg}[\mathrm{E}]$ and $\mathrm{Tg}[\mathrm{R}]$ transgenes for dox-inducible expression of S/c26a4. (A) BAC clone RP23-265L9 encoding mouse genomic Slc26a4 is shown at the top of the figure. (B) $\mathrm{Tg}[\mathrm{E}]$ was generated by replacement of the translation start codon in exon 2 of S/c26a4 with the reverse tetracycline-controlled transactivator (rtTA2 ${ }^{S}-M 2$ ) followed by a neomycin resistance cassette $\left(N e o^{R}\right)$. (C) $\mathrm{Tg}[\mathrm{R}]$ comprises AcGFP (encoding aequorea coerulescens GFP) and S/c26a4 cDNAs under bidirectional control of the tetracycline operator $\left(\right.$ tetO $_{7}$ ) and CMV promoters. pA, polyadenylation signal sequence; SP6, SP6 RNA polymerase promoter; T7, T7 RNA polymerase promoter.

We performed a converse analysis by varying the time point of dox discontinuation (D) for $\operatorname{Tg}[\mathrm{E}]$; $\mathrm{Tg}[\mathrm{R}]$;Slc26a4 ${ }^{\Delta / \Delta}$ mice that had been administered dox since conception. Western blot analysis showed the half-life of pendrin to be approximately 18 hours after discontinuation of dox, with less than $1 \%$ of pendrin present in DP6 tissues at P25-P35 (not shown). When dox was discontinued at or before $\mathrm{E} 15.5$, the $\mathrm{Tg}[\mathrm{E}] ; \mathrm{Tg}[\mathrm{R}] ; \operatorname{Slc} 264^{\Delta / \Delta}$ mice were deaf, with ABR thresholds indistinguishable from those of Slc26a ${ }^{4 / \Delta}$ controls (Figure 4B). Delaying the discontinuation of dox until E16.5 produced a significant improvement in ABR thresholds (Figure 4B), although the $\mathrm{EP}$ and endolymphatic $\mathrm{pH}$ were severely reduced even when dox had been discontinued 1 day later at E17.5 (Figure 5, $\mathrm{A}$ and $\mathrm{B}$ ). In contrast, perilymphatic $\mathrm{pH}$ remained normal (Figure 5C). A further delay of dox discontinuation until P2 led to thresholds that were within the range of normal-hearing Slc26a $4^{\Delta /+}$ controls (Figure 4B), and a delay until $\mathrm{P} 6$ led to endolymphatic $\mathrm{pH}$ values that were also within normal limits of Slc26a $4^{4 /+}$ controls (Figure 5B). Delaying dox discontinuation until P6 improved the EP, but did not restore it to normal levels (Figure 5A).

Although several dox initiation and discontinuation time points resulted in differences between better- and worse-hearing ear thresholds, the differences appeared to be larger for discontinuation paradigms (Figure 4). The mean ABR thresholds for DE19.5, DP0, or DP1 mice collectively reflect a high prevalence of unilateral hearing loss, since the mean ABR thresholds of better-hearing ears were within the range of normal-hearing Slc26a4 ${ }^{4 /+}$ controls (Figure 4B).

Morphology of IE18.5 and DE17.5 inner ears. The effect of time of Slc26a4 expression on morphogenesis of the membranous labyrinth was evaluated by varying the time point of dox initiation to E16.5 or E18.5 and paint filling a portion of the membranous labyrinth of $\operatorname{Tg}[\mathrm{E}] ; \mathrm{Tg}[\mathrm{R}] ; S l c 264^{\Delta / \Delta}$ mice at P3 (Figure 6, A-D) to visualize their gross morphology. The cochlear duct appeared normal. The endolymphatic sac and duct appeared slightly enlarged when dox was initiated at E16.5, but were very enlarged when dox initiation was delayed until E18.5 (Figure 6, B and C). In contrast, these structures appeared normal when dox was initiated at E13.5 (data not shown). We also evaluated the effect of time of Slc26a4 expression on the size of the vestibular aqueduct in adult (P28 to P109) $\operatorname{Tg}[\mathrm{E}] ; \operatorname{Tg}[\mathrm{R}] ; S l c 26 a 4^{\Delta / \Delta}$ mice (Figure 6, E-H). Initiation of dox at E16.5 and E18.5 led to an EVA with a 3 - and 25-fold increase in cross-sectional area, respectively (Figure 6, F and G). The crosssectional area in $\operatorname{Slc} 26 a 4^{\Delta / \Delta}$ mice was 106-fold larger compared with that in Slc26a4 ${ }^{4 /+}$ control mice (Figure 6, E and $\mathrm{H}$ ). These results indicate a strong effect of expression of Slc26a4 on morphogenesis of the vestibular aqueduct and endolymphatic sac and duct during the late embryonic period beginning at or near E16.5. In contrast, $\operatorname{Tg}[\mathrm{E}] ; \operatorname{Tg}[\mathrm{R}] ; \operatorname{Slc} 26 a 4^{\Delta / \Delta}$ DE17.5, and even DE16.5, mice had no endolymphatic enlargement (not shown).

Morphology of IE18.5 and DE17.5 cocblear ducts. We used light microscopy to evaluate the cochlear ducts of $\operatorname{Tg}[\mathrm{E}] ; \mathrm{Tg}[\mathrm{R}] ; \operatorname{Slc26} \mathrm{a}^{4 / \Delta}$ DE17.5 mice at P25 to P35 (Figure 7B). The cochlear ducts did not differ in appearance from those of $\mathrm{Tg}[\mathrm{E}] ; \mathrm{Tg}[\mathrm{R}] ; \operatorname{Slc26a4^{4/+}}$ controls (Figure 7A). We could not identify structural abnormalities of the spiral ganglion, stria vascularis, or other regions of the lateral wall to account for the hearing loss observed in DE17.5 mice. The organ of Corti and hair cells appeared intact, which was confirmed by scanning electron microscopy (Figure 7F).

We also analyzed $\operatorname{Tg}[\mathrm{E}] ; \operatorname{Tg}[\mathrm{R}] ; S l c 26 a 4^{\Delta / \Delta} \mathrm{IE} 18.5$ mice at P25 to P30 (Figure 7C). In contrast to Slc26a4 ${ }^{\Delta / \Delta}$ cochleae (Figure 7D), the Reissner membrane was not distended, but was collapsed onto the spiral limbus and tectorial membrane (Figure 7C). The organ of Corti, spiral ganglion, spiral ligament, and stria vascularis were indistinguishable from those of Slc26a $4^{\Delta /+}$ controls (Figure 7, A and $\mathrm{C}$ and $\mathrm{E}$ and $\mathrm{G}$ ). The hair cells showed normal uptake following a brief exposure to the styryl membrane dye AM1-43 (not shown), a fixable analog of FM1-43, which is thought to reflect the presence of functional mechanotransduction channels open at rest (22). The uptake of AM1-43 suggests that $\mathrm{Tg}[\mathrm{E}] ; \mathrm{Tg}[\mathrm{R}] ; \mathrm{Slc}_{26} 4^{\Delta / \Delta} \mathrm{IE} 18.5$ hair cells are functionally intact.

To further characterize the $\operatorname{Tg}[\mathrm{E}] ; \operatorname{Tg}[\mathrm{R}] ; \operatorname{Slc}_{26} \mathrm{4}^{\Delta / \Delta} \mathrm{IE} 18.5$ cochleae, we measured stria vascularis thickness by light microscopy. The mean thickness $(21.1 \pm 2.1 \mu \mathrm{m} ; n=5)$ of $\mathrm{Tg}[\mathrm{E}] ; \mathrm{Tg}[\mathrm{R}] ; \operatorname{Slc} 26 a 4^{\Delta / \Delta}$ IE18.5 stria vascularis showed no difference $(P=0.35)$ from that $(21.9 \pm 1.6 \mu \mathrm{m} ; n=5)$ of $\mathrm{Tg}[\mathrm{E}] ; \mathrm{Tg}[\mathrm{R}] ; S l c 26 a 4^{\Delta /+}$ controls, whereas it was significantly larger $(P=0.012)$ than the value $(14.5 \pm 1.2 \mu \mathrm{m}$; $n=5)$ for Slc26a4 $4^{\Delta / \Delta}$ mice. Therefore there is no overt abnormality of stria vascularis structure in $\mathrm{Tg}[\mathrm{E}] ; \mathrm{Tg}[\mathrm{R}] ; S_{l c 26 a 4^{\Delta / \Delta}} \mathrm{IE} 18.5$ cochleae to account for the reduced EP.

Kcnj10 and pendrin expression in IE18.5 cochleae. Since loss of functional Kcnj10 protein in intermediate cells of the stria vascularis is associated with loss of the EP in $\operatorname{Slc} 26 a 4^{\Delta / \Delta}$ mice $(16,23)$, we used anti-Kcnj10 antibodies to evaluate Kcnj10 protein expression in $\operatorname{Tg}[\mathrm{E}] ; \operatorname{Tg}[\mathrm{R}] ; S l c 26 a 4^{\Delta / \Delta}$ IE18.5 cochleae (Figure 8, A and C). We observed Kcnj10 immunoreactivity in the stria vascularis that did not significantly differ from that in $\mathrm{Tg}[\mathrm{E}] ; \mathrm{Tg}[\mathrm{R}] ; \operatorname{Slc} 26 \mathrm{a}^{\Delta /+}$ controls (Figure 8B). Therefore a reduction in overall Kcnj10 protein 


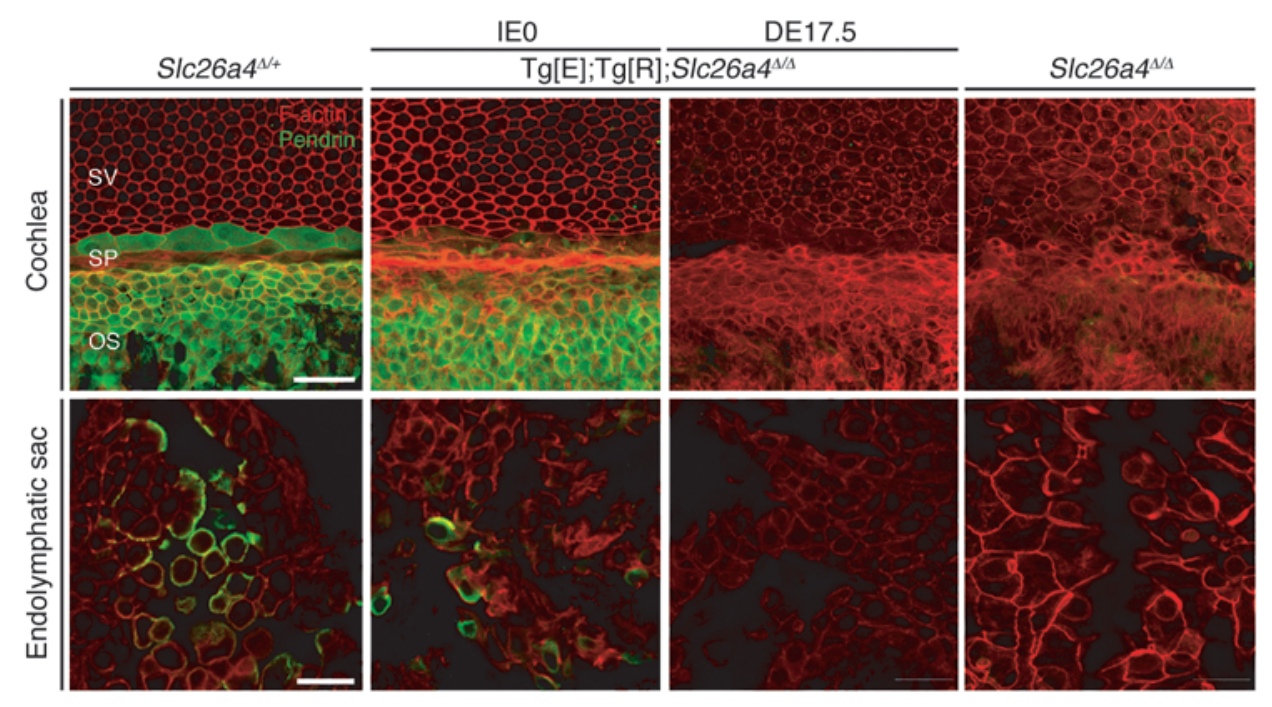

\section{Figure 3}

Immunohistochemical analysis of dox-inducible expression of pendrin at 1 month of age. Anti-pendrin antibodies (PB826) were used to immunostain the lateral wall of basal cochlea and endolymphatic sac of Tg[E];Tg[R];S/c26a4 ${ }^{\Delta / \Delta}$ IEO and DE17.5 mice. S/c26a $4^{\Delta / \Delta}$ and S/c26a4 $4^{\Delta /+}$ tissues are shown as negative and positive expression controls and for antiserum validation. PB826 immunoreactivity in IE0 but not DE17.5 tissues indicates that pendrin expression in $\mathrm{Tg}[\mathrm{E}] ; \mathrm{Tg}[\mathrm{R}] ; S / c 26 a 4^{\Delta / \Delta}$ mice is inducible in the presence of dox but not in its absence. Results for the apical turn of the cochlea are similar to those shown for the basal turn. Green fluorescence derived from AcGFP encoded by the responder transgene (Figure 2C) was not detectable. Scale bars: $50 \mu \mathrm{m}$. OS, outer sulcus.

levels does not underlie the reduced $\mathrm{EP}$ in $\operatorname{Tg}[\mathrm{E}] ; \operatorname{Tg}[\mathrm{R}] ; \operatorname{Slc} 26 \mathrm{4}^{\Delta / \Delta}$ IE18.5 mice. We also stained the cochlea (Figure 8F) and endolymphatic sac (Figure 8I) of $\mathrm{Tg}[\mathrm{E}] ; \mathrm{Tg}[\mathrm{R}] ; S l c 26 a 4^{\Delta / \Delta} \mathrm{IE} 18.5$ and genotype control mice at P25 to P35 with anti-pendrin antibodies. $\mathrm{Tg}[\mathrm{E}] ; \mathrm{Tg}[\mathrm{R}] ; S l c 26 a 4^{\Delta / \Delta}$ IE18.5 cochlear pendrin immunoreactivity was undetectable or negligible in comparison with that in controls. This indicates that the absence of pendrin through E18.5 results in irreversible loss of inducibility of Slc26a4 expression in $\operatorname{Tg}[\mathrm{E}] ; \operatorname{Tg}[\mathrm{R}] ; S l c 26 a 4^{\Delta / \Delta}$ cochleae.

\section{Discussion}

Here we describe a mouse line in which all pendrin is derived from dox-induced expression of an Slc26a4 cDNA transgene. Our data reveal a developmental period, E16.5 to P2, during which expression of Slc26a4 is required for acquisition of normal hearing (Figure 4), although the EP did not reach normal levels (Figure 5A). This may suggest that pendrin is required over a longer period for the development of a normal EP. It could also indicate that $\mathrm{Tg}[\mathrm{E}] ; \mathrm{Tg}[\mathrm{R}] ; \operatorname{Slc} 26 a 4^{\Delta / \Delta}$ mice are unable to acquire a normal EP even in the presence of continuous dox exposure. Continued expression of pendrin through P6 increased the EP, but not to normal levels. The onsets of the critical intervals for dox initiation (E16.5) and discontinuation (E15.5) differ by 1 day. This likely reflects the slower kinetics associated with discontinuation of dox and pendrin turnover. The results of the discontinuation and initiation models are thus consistent with each other and collectively suggest that pendrin is required during a limited period at or shortly after E16.5 for development of normal hearing.

The critical time interval for pendrin expression corresponds to the period during which the cochlea grows rapidly $(20,24)$. The transiency of this critical time interval for pendrin expression could reflect a temporary period of sensitivity of inner ear development to disruptions of endolymph $\mathrm{pH}$ or ionic homeostasis. It is also possible that pendrin mediates exchange of an anion, base, or both that is only temporarily required for normal inner ear physiology and development. $\mathrm{I}^{-}$is a known in vitro exchange substrate of pendrin (25), and its concentration probably rises soon following the onset of type 2 deiodinase activity in the late embryonic cochlea (26). Cochlear concentrations and mechanism of $\mathrm{I}^{-}$homeostasis are unknown but, if there were not a mechanism to disperse $\mathrm{I}^{-}$, an excess could conceivably exert a toxic effect on cells within the cochlea, inhibit deiodinase reaction(s) leading to cochlear hypothyroidism (27), or produce a combination of these effects. Finally, the dependence of renal $\mathrm{Na}^{+}$reabsorption on luminal $\mathrm{HCO}_{3}{ }^{-}$secretion and alkalinization by pendrin (28) raises the possibility of an analogous role in embryonic endolymph. Although $\mathrm{K}^{+}$is the major osmolyte in mature endolymph, the composition of embryonic endolymph is unknown and $\mathrm{Na}^{+}$may be an important developmental osmolyte. A decrease in $\mathrm{Na}^{+}$reabsorption thus might be poorly tolerated, leading to increased osmotic pressure, scala media acidification and expansion, and EVA.

Pendrin is not required, or is required only at undetectable low levels, for acquisition of normal hearing in a normally formed mature inner ear. This raises the possibility that replacement or upregulation of pendrin in a mature ear might not reverse or prevent hearing loss caused by SLC26A4 mutations in human subjects. However, we have not yet determined whether the low EP associated with normal hearing in $\mathrm{Tg}[\mathrm{E}] ; \mathrm{Tg}[\mathrm{R}] ; S l c 26 a 4^{\Delta / \Delta} \mathrm{DP} 6$ ears leads to later-onset hearing loss. If so, upregulation of pendrin may still be a logical therapeutic objective.

One advantage of inducible Slc26a4 expression is the opportunity to distinguish early primary pathogenetic events from later secondary effects. We were able to distinguish functional consequences associated with loss of pendrin expression in a mature cochlea versus secondary effects of the severe structural malformations associated with complete pendrin deficiency. Both $\operatorname{Tg}[\mathrm{E}] ; \mathrm{Tg}[\mathrm{R}] ; \operatorname{Slc26a4^{\Delta /\Delta }}$ 
A

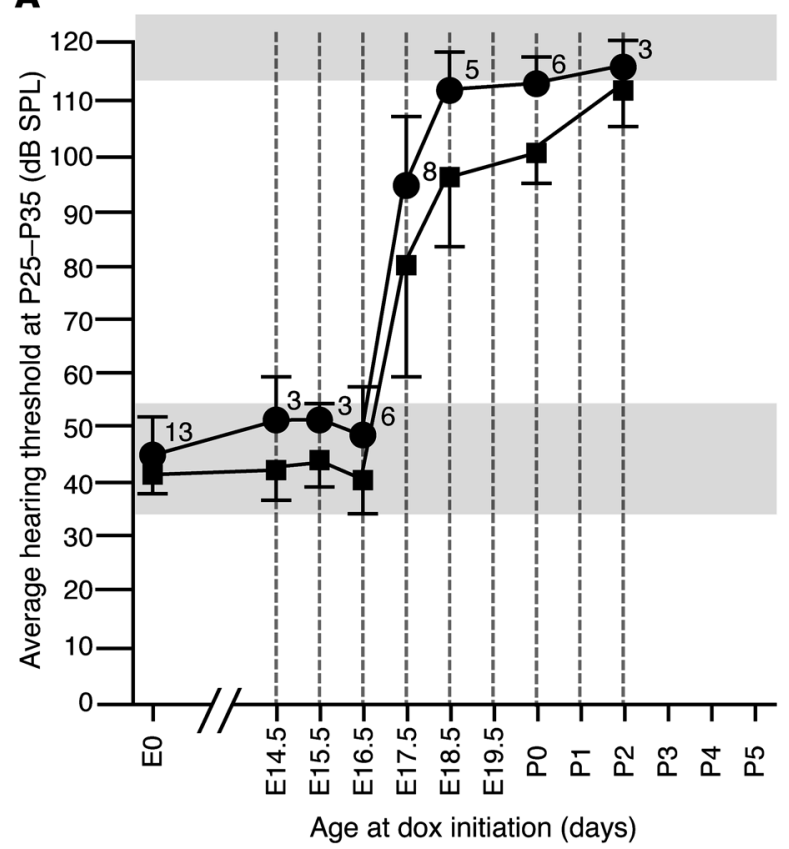

B

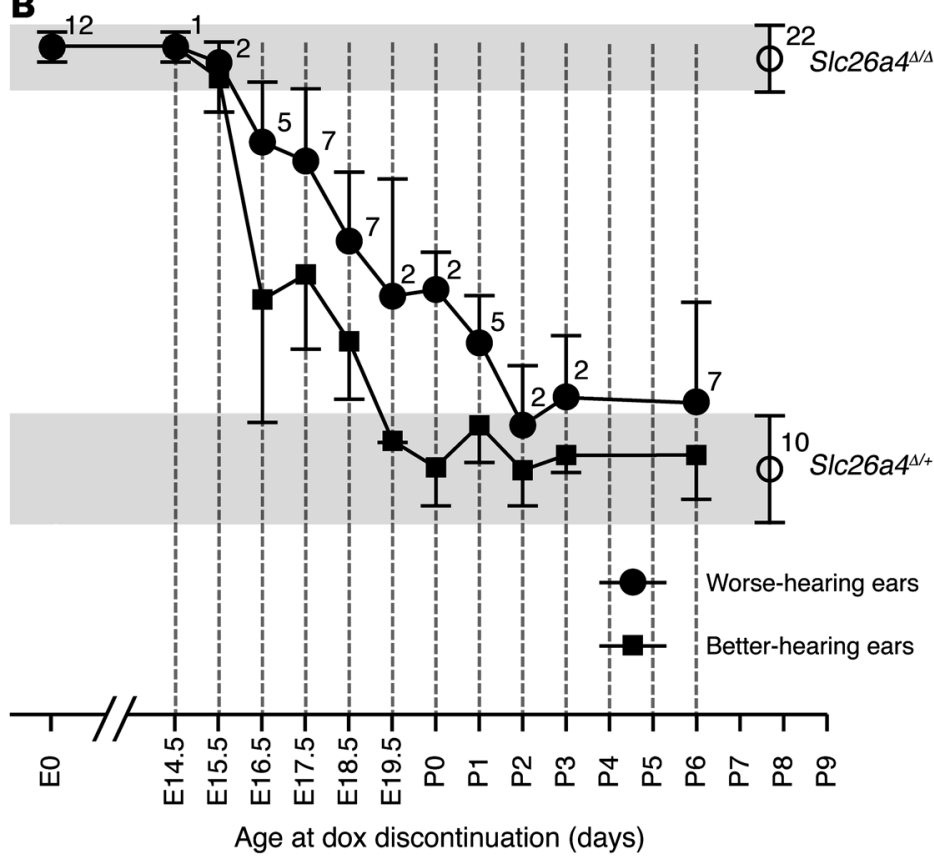

Figure 4

ABR thresholds in response to a click stimulus measured at P25 to P35. Mean \pm SD thresholds are shown for better- and worse-hearing ears from groups of $\mathrm{Tg}[\mathrm{E}] ; \mathrm{Tg}[\mathrm{R}] ; S / c 26 a 4^{\Delta / \Delta}$ mice according to time point of initiation (A) or discontinuation (B) of dox administration. Numerals next to data points indicate the number of tested mice. The mean \pm SD binaural thresholds for S/c26a4 ${ }^{\Delta / \Delta}$ and S/c26a4 $4^{\Delta /+}$ control mice on the same mixed genetic background are shown as shaded regions. $\mathrm{Tg}[\mathrm{E}] ; \mathrm{Tg}[\mathrm{R}] ; S / c 26 a 4^{\Delta / \Delta}$ mice require dox administration from $\mathrm{E} 16.5$ to $\mathrm{P} 2$ in order to acquire normal hearing at P25 to P35.

IE18.5 (dox initiated at E18.5) and DE17.5 (dox discontinued at $\underline{E} 17.5)$ mice had severe to profound hearing loss, yet scala media enlargement was present in IE18.5 mice only during embryonic development (Figure 7C and ref. 20) and was not observed in DE17.5 mice (Figure 7B). Therefore scala media expansion is unlikely to be a sole direct cause of loss of EP and hearing.

We observed scala media acidification in both $\mathrm{Tg}[\mathrm{E}] ; \mathrm{Tg}[\mathrm{R}]$; Slc26a4 ${ }^{\Delta / \Delta}$ IE18.5 and DE17.5 mice, confirming that cochlear endolymph acidification may indeed be an early pathogenetic event ultimately leading to reduction of the EP and hearing in Slc26a4deficient ears. The reduction of EP might be mediated by functional degradation of the normally tight permeability barrier of the basal stria vascularis that is required for maintenance of the EP (29). However, our observation of normal overall levels of Kcnj10 immunoreactivity (Figure 8, A and C) does not rule out a decrease of functional Kcnj10 at the plasma membrane of intermediate cells of the stria vascularis that generate the EP. The loss of the EP and hearing in Slc26a4-deficient mice could result from either of these or other mechanisms that disrupt the function of the stria vascularis and lateral wall of the cochlea.

The results of this study and others (16) suggest that preserving or supporting strial function and thereby preventing hair cell loss could be a primary target of strategies to prevent or retard hearing loss caused by SLC26A4 mutations. Prevention of scala media acidification could be another goal.

One difference between $\operatorname{Slc} 26 a 4^{4 / \Delta}$ mice and $\operatorname{Tg}[\mathrm{E}] ; \operatorname{Tg}[\mathrm{R}] ; \operatorname{Slc} 26 a 4^{\Delta / \Delta}$ IE18.5 or DE17.5 mice is the lack of endolymphatic hydrops (scala media expansion with distention of Reissner membrane) in the adult cochleae of the inducible expression models. The reported time line of endolymphatic enlargement in Slc26a4 $4^{\Delta / \Delta}$ mice (20) suggests that $\mathrm{Tg}[\mathrm{E}] ; \mathrm{Tg}[\mathrm{R}] ; S l c 26 a 4^{\Delta / \Delta} \mathrm{IE} 18.5$ cochleae also develop endolymphatic hydrops with distention of Reissner membrane until E18.5. The distended Reissner membrane subsequently collapses onto the tectorial membrane by 1 month of age (Figure 7) upon reversal of endolymphatic hydrops with induction of pendrin expression at E18.5. In contrast, $\operatorname{Tg}[\mathrm{E}] ; \mathrm{Tg}[\mathrm{R}] ; \operatorname{Slc26a4^{4/\Delta }}$ DE17.5 mice probably never develop endolymphatic hydrops, since DE16.5 inner ears show no endolymphatic enlargement.

Induction of Slc26a4 expression at E18.5 did not rescue the ability to express pendrin expression in the outer sulcus of $\operatorname{Tg}[\mathrm{E}] ; \operatorname{Tg}[\mathrm{R}] ; S l c 26 a 4^{\Delta / \Delta}$ IE18.5 cochleae (Figure 8). This finding likely reflects a developmental disruption or retardation of nonsensory epithelial cell function in the outer sulcus or spiral prominence (i.e., the cells that express pendrin).

The etiopathogenesis of incremental and progressive hearing loss in humans with SLC26A4 mutations was not addressed by our study. Elucidation of the factors underlying hearing loss stability is important, since stabilization of hearing in humans with EVA is an important therapeutic goal. $\operatorname{Tg}[\mathrm{E}] ; \mathrm{Tg}[\mathrm{R}] ; \operatorname{Slc} 26 a 4^{\Delta / \Delta}$ mice may be used to explore these issues, since the IE18.5 and DE17.5 paradigms result in residual hearing. The hearing loss observed with these paradigms, particularly the asymmetry and unilaterality associated with the DE19.5, DP0, and DP1 paradigms, is remarkable for its similarity to some human EVA phenotypes. Characterization of the natural history of hearing loss associated with these dox administration paradigms in $\mathrm{Tg}[\mathrm{E}] ; \mathrm{Tg}[\mathrm{R}] ; S l c 26 a 4^{\Delta / \Delta}$ mice will be needed to fully explore and exploit this model of human hearing loss associated with EVA. 


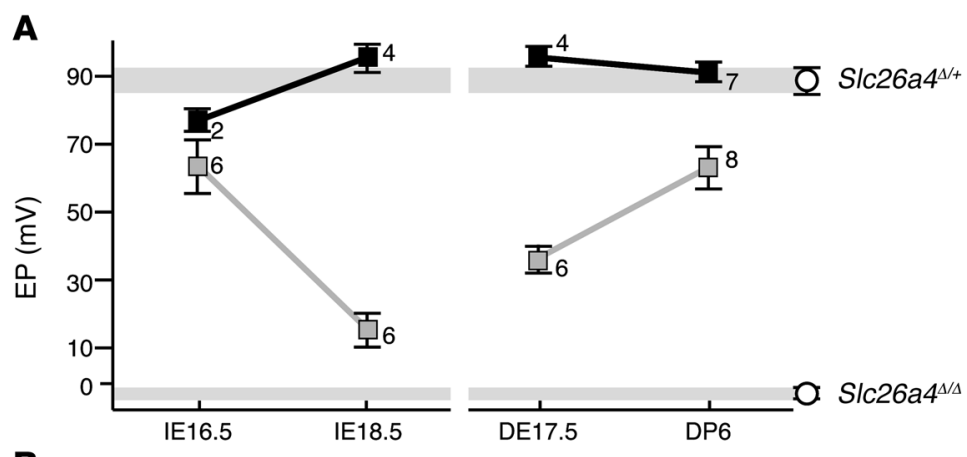

B
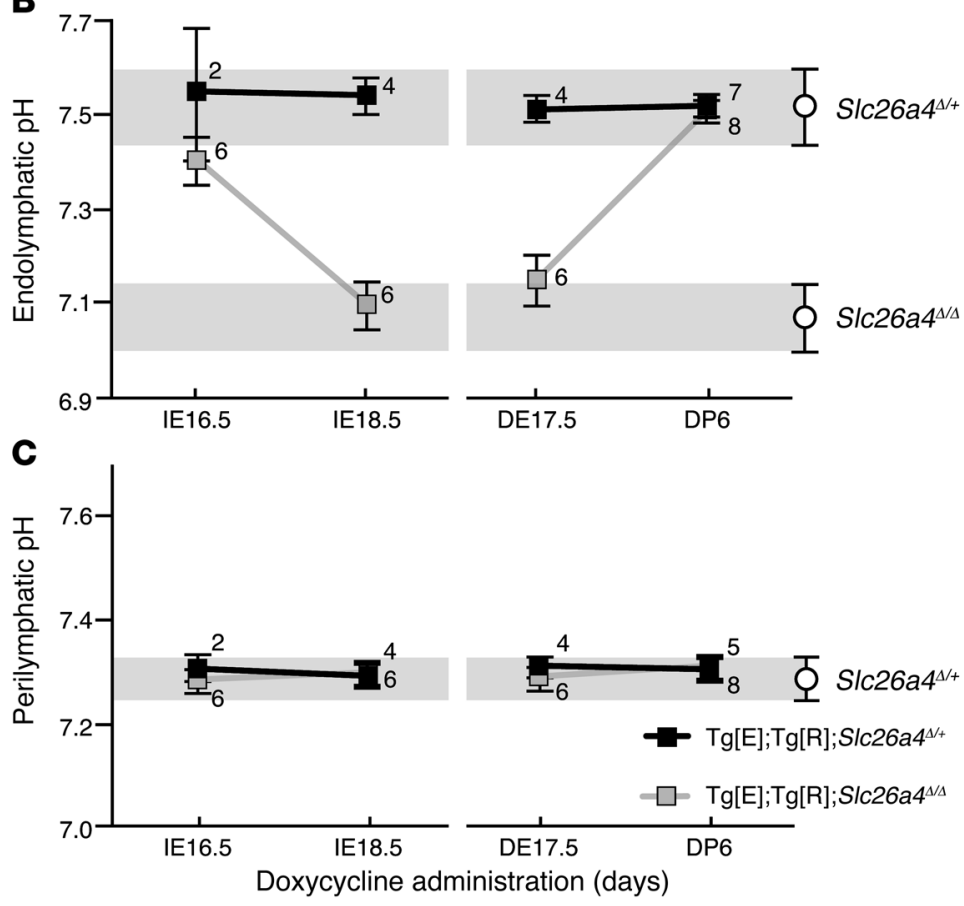

Figure 5

$\mathrm{EP}$, endolymphatic $\mathrm{pH}$, and perilymphatic $\mathrm{pH}$ values measured at $\mathrm{P} 25$ to $\mathrm{P} 56$. Mean \pm SEM values of EP $(\mathbf{A})$ and endolymphatic $\mathrm{pH}(\mathbf{B})$ are shown for $\operatorname{Tg}[\mathrm{E}] ; \mathrm{Tg}[\mathrm{R}] ; S / c 26 a 4^{\Delta / \Delta}$ mice and $\mathrm{Tg}[\mathrm{E}] ; \mathrm{Tg}[\mathrm{R}] ; S / c 26 a 4^{\Delta /+}$ littermate controls. Numerals next to data points in all panels indicate numbers of tested mice. (C) Perilymphatic $\mathrm{pH}$ control values do not vary among dox administration or genotype groups. Published mean \pm SEM values for SIc26a4 ${ }^{\Delta / \Delta}$ and SIc26a4 $4^{\Delta /+}$ controls (13) are shown as shaded regions. The EP and endolymphatic $\mathrm{pH}$ in $\mathrm{Tg}[\mathrm{E}] ; \mathrm{Tg}[\mathrm{R}] ; \mathrm{S} / c 264^{\Delta / \Delta} \mathrm{IE} 18.5$ and DE17.5, but not IE16.5, ears were reduced in comparison with values for $\mathrm{Tg}[\mathrm{E}] ; \mathrm{Tg}[\mathrm{R}] ; \mathrm{S} / \mathrm{c} 26 \mathrm{a} 4^{\nu+}$ controls. The EP, but not $\mathrm{pH}$, in $\mathrm{Tg}[\mathrm{E}] ; \mathrm{Tg}[\mathrm{R}] ; S / c 26 a 4^{\Delta / \Delta} \mathrm{DP} 6$ ears was slightly reduced.

\section{Methods}

$\mathrm{Tg}[$ E]. BAC clone RP23-265L9 (185,766 bp; BACPAC Resources Center) encoding WT C57BL/6J mouse genomic Slc26a4 was used to construct Tg[E] using red/ET recombination technology (Gene Bridges Gmbh; Figure 2). RP23-265L9 was assumed to include all cis-regulatory elements required for inner ear expression, since we found that a similar unmodified BAC (RP23-122C13) restored normal auditory and vestibular function in Slc26a $44^{\Delta / \Delta}$ mice (data not shown). The translation start codon of Slc26a4 located in exon 2 was replaced with $\mathrm{rtTA}^{\mathrm{S}}-\mathrm{M} 2 / \mathrm{Neo}^{\mathrm{R}}$. We used electroporation $(2.3 \mathrm{kV}, 25 \mu \mathrm{F}, 200 \Omega)$ to transform electrocompetent E. coli, already containing BAC RP23-265L9, with pSC101-BAD-gbaA(tet $\left.{ }^{\mathrm{r}}\right)$ $(30,31)$, and identified a clone containing both PSC101-BAD-gbaA $\left(\right.$ tet $\left.^{t}\right)$ and
RP23-265L9. pSC101-BAD-gbaA(tet ${ }^{\mathrm{r}}$ ) codes for 2 bacteriophage proteins that promote homologous recombination using 42-bp homology arms.

We used KOD Hot Start DNA polymerase (MD Biosciences) and PAGE-purified primers 92 and 93 (Supplemental Table 1; supplemental material available online with this article; doi:10.1172/JCI59353DS1) to generate 3-kb PCR products comprising $\mathrm{rtTA}^{\mathrm{S}}-\mathrm{M} 2 / \mathrm{Neo}^{\mathrm{R}}$ flanked by the last $50 \mathrm{bp}$ of the $5^{\prime}$ UTR and the first $50 \mathrm{bp}$ of the open reading frame of mouse Slc26a4. Electrocompetent E. coli containing pSC101BAD-gbaA(tet ${ }^{\mathrm{r}}$ ) and RP23-265L9 were transformed with these PCR products by electroporation $(2.3 \mathrm{kV}, 25 \mu \mathrm{F}, 200 \Omega)$ and incubated overnight at $37^{\circ} \mathrm{C}$. PCR analyses of 8 colonies identified 2 with successful recombination. BACs were sequenced to confirm the expected recombination event and purified for microinjection as described. BAC identity and integrity were confirmed by NotI (New England BioLabs) digestion and pulsed-field gel electrophoresis, as well as fingerprint analyses of digestion products of BamHI, SacII, KpnI, and NdeI.

$\mathrm{Tg}[R]$. We used the pTRE-Tight-Bi-AcGFP1 vector (Clontech) to generate a bidirectional $\mathrm{Tg}[\mathrm{R}]$ that also encodes SLC26A4 (pendrin) (Figure 2). Total RNA was isolated from E13.5 C57BL/6J mouse embryos using the RNeasy Mini Kit (QIAGEN). cDNA was synthesized using Superscript III First-Strand Synthesis (Invitrogen). We used primers 189 and 200 (Supplemental Table 1) to PCR amplify a Kozak consensus sequence (GCCACC) (32) followed by mouse Slc26a4 cDNA (c.1A to c.2343G; GenBank NM_011867). The amplification product was cloned into the BamHI and NotI sites of pTRE-Tight-BiAcGFP1. We digested the recombinant vector with ApaLI and DrdI to liberate and purify the 4412-bp TRE-Tight-Bi-AcGFP1Slc26a4 fragment from vector sequences.

Transgenic mice. Recombinant RP23-265L9 BAC and linearized TRE-Tight-Bi-AcGFP1-Slc26a4 DNA were microinjected into $(\mathrm{C} 57 \mathrm{BL} / 6 \mathrm{~J} \times \mathrm{SJL}) \mathrm{F} 2$ mouse oocytes at the Transgenic Core Facility of the University of Michigan. Two $\mathrm{Tg}[\mathrm{E}]$ founder lines (numbers 928 and 946) and $5 \mathrm{Tg}[\mathrm{R}]$ founder lines (numbers $1,35,37,66,114$ ) were maintained by crossing to $\mathrm{C} 57 \mathrm{BL} / 6 \mathrm{~J}$, and the Slc26a4s line was intercrossed to maintain its isogenic $129 \mathrm{~Sv}$ background. The Mouse Genome Informatics-approved locus symbols are $\operatorname{Tg}\left(\mathrm{RP} 23-265 \mathrm{~L} 9 / \mathrm{rtTA}^{\mathrm{S}}\right.$-M2/ $\left.\mathrm{Neo}^{\mathrm{R}}\right) 1 \mathrm{Ajg}$ for $\mathrm{Tg}[\mathrm{E}]$ and $\mathrm{Tg}(\mathrm{AcGFP} / \mathrm{TRE} / \mathrm{Slc} 26 \mathrm{a} 4) 2 \mathrm{Ajg}$ for $\mathrm{Tg}[\mathrm{R}] .\left(\mathrm{Tg}[\mathrm{E}]^{\mathrm{Tg} /+} ; \operatorname{Slc}_{2} 6 a 4^{+/+} \times \operatorname{Slc} 26 a 4^{\Delta / \Delta}\right) \mathrm{N}_{1}-\mathrm{Tg}[\mathrm{E}]^{\mathrm{Tg} /+} ; \operatorname{Slc}_{2} 6 a 4^{\Delta /+}$ and $\left[\left(\mathrm{Tg}[\mathrm{R}]^{\mathrm{Tg} /+} ; \operatorname{Slc} 26 a 4^{+/+} \times \operatorname{Slc} 26 a 4^{\Delta / \Delta}\right) \mathrm{N}_{1}-\mathrm{Tg}[\mathrm{R}]^{\mathrm{Tg} /+} ;\right.$ Slc26a4 $4^{\Delta /+} \times$ Slc26a $\left.4^{\Delta / \Delta}\right] \mathrm{N}_{2}-\mathrm{Tg}[\mathrm{R}]^{\mathrm{Tg} /+} ;$ Slc26a $4^{\Delta / \Delta}$ mice were crossed to generate experimental animals.

Genotype analysis. Genomic DNA was prepared from tail clips using QIAGEN DNeasy (QIAGEN) or the Maxwell 16 System (Promega). We performed PCR with Taq polymerase (GenScript) to genotype mice for the presence of $\operatorname{Tg}[\mathrm{E}]$ (primer pairs 113/114 and 115/116; Supplemental Table 1) or $\mathrm{Tg}[\mathrm{R}]$ (primer pair 177/178; Supplemental Table 1). The published assay for Slc26a4 $4^{\Delta}$ genotype analysis (19) cannot distinguish WT endogenous Slc26a4 from the same sequence within $\mathrm{Tg}[\mathrm{E}]$. We therefore used the D12Mit270 short tandem repeat (STR) marker $46 \mathrm{~kb}$ upstream of endogenous Slc26a4, but not encoded within $\mathrm{Tg}$ [E], to differentiate the $129 / \mathrm{SvEv}$ allele flanking the endogenous Slc26a ${ }^{4}$ locus from the $(\mathrm{C} 57 \mathrm{BL} / 6 \mathrm{~J} \times \mathrm{SJL} / \mathrm{J})$ allele flanking endogenous Slc26a4 $4^{+}$. Similarly, we also identified and genotyped a novel STR marker $233 \mathrm{~kb}$ downstream with primers 127-2 and 128-2 (Supplemental Table 1) to differentiate Slc26a4s (129/SvEv) from Slc26a4+ (C57BL/6J X SJL/J) alleles. PCR amplifications 


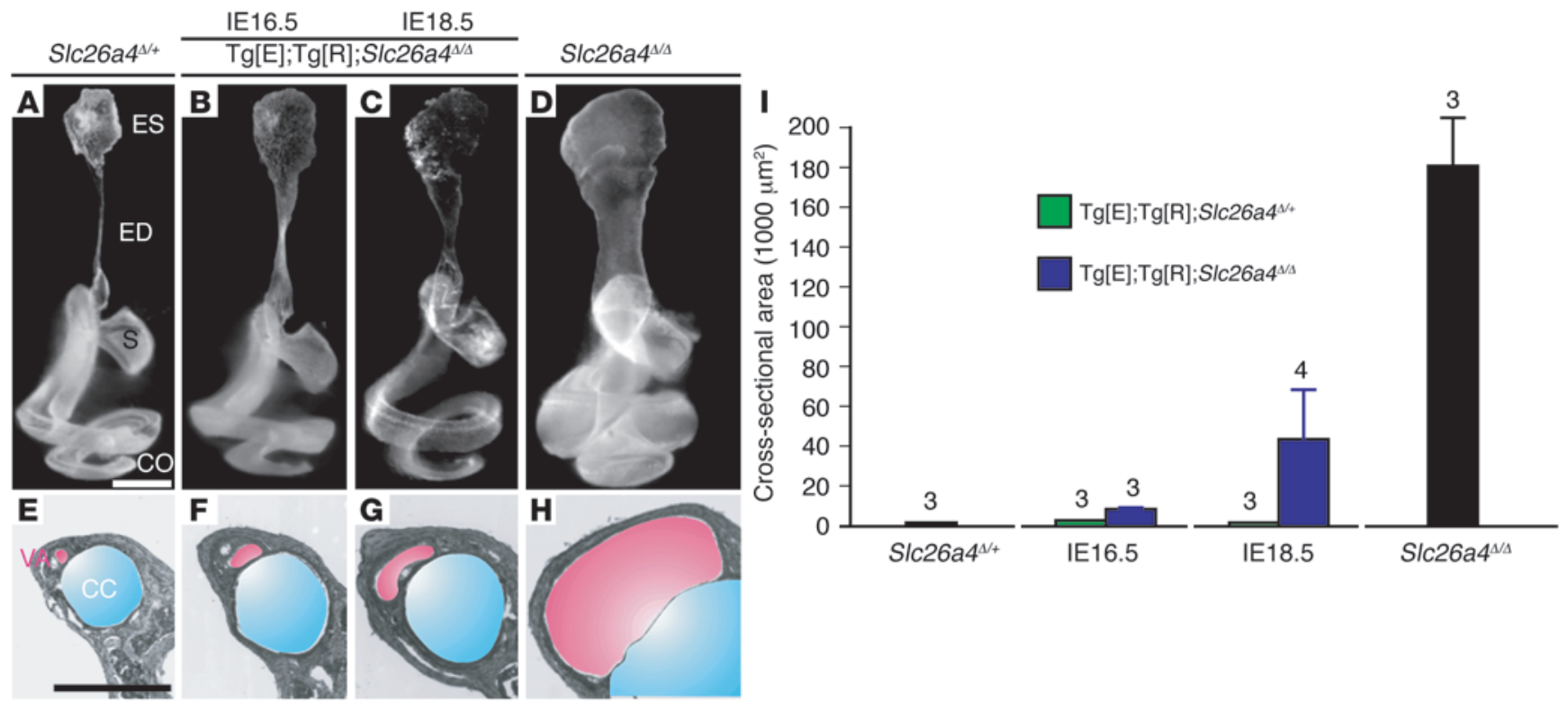

Figure 6

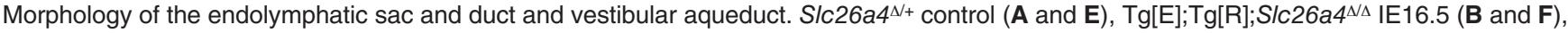

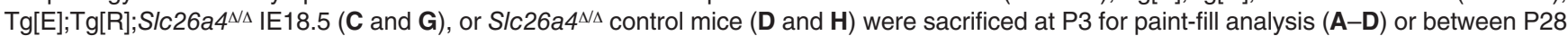
and P109 for cross-sectional histopathologic measurement of the vestibular aqueduct (VA, shaded pink) adjacent to the common crus (CC, shaded blue; E-H). (I) Mean \pm SD values are shown for cross-sectional areas of the vestibular aqueduct. Numbers of mice are indicated. Scale bars: $500 \mu \mathrm{m}$ (A, applies to A-D; E, applies to E-H). Progressive delays of initiation of pendrin expression to E16.5 and E18.5 result in abnormal enlargement of the endolymphatic duct and sac and vestibular aqueduct. ES, endolymphatic sac; ED, endolymphatic duct; S, saccule; CO, cochlea.

comprised a 2-minute denaturation at $94^{\circ} \mathrm{C}, 35$ step-cycles of $30 \mathrm{sec}-$ onds at $94^{\circ} \mathrm{C}, 30$ seconds at $55^{\circ} \mathrm{C}$, and 45 seconds at $72^{\circ} \mathrm{C}$, followed by a 10-minute elongation at $72^{\circ} \mathrm{C}$.

dox. Drinking water containing $0.2 \mathrm{~g}$ dox hyclate (Sigma-Aldrich) and $5 \mathrm{~g}$ sucrose (MP Biomedicals) per $100 \mathrm{ml}$ of reagent-grade water was prepared twice weekly and administered ad libitum. For the dox initiation paradigm (denoted by I), dox water was substituted for dox-free water at the indicated embryonic or postnatal age estimated from the date of maternal vaginal plugging. For the dox discontinuation paradigm (denoted by D), dox water was provided to the mother from the time of mating and substituted with dox-free water at the indicated embryonic or postnatal age. Dox initiation or discontinuation is denoted by an I or D, respectively, followed by the developmental time point (day) at which the switch occurred.

Antibodies. Anti-pendrin antisera were generated by immunizing rabbits (Covance) with a synthetic peptide ( $\mathrm{NH}_{2}$-CEELDVQDEAMRRLAS; Princeton BioMolecules) that had a noncoding aminoterminal cysteine for linkage to an affinity matrix and amino acids 766-780 of the C terminus of mouse pendrin (NCBI NP_035997). Three rabbits were immunized to generate PB824, PB825, and PB826 antisera. We purified anti-pendrin IgG with immobilized protein A (Pierce) followed by affinity column purification using an AminoLink Plus Immobilization Kit (Pierce).

Figure 7
Polyclonal rabbit antibodies against rat $\mathrm{Kenj} 10\left(\mathrm{~K}_{\mathrm{ir}} 4.1, \mathrm{Kir} 1.2\right)$ were purchased from Alomone Labs (\#APC-035).

Immunobistochemistry. Whole-mounted mouse cochleae, vestibules, and endolymphatic sacs were immunostained essentially as described for pendrin (15) and Kcnj10 (16) with some differences: sections were 10- $\mu \mathrm{m}$ thick,

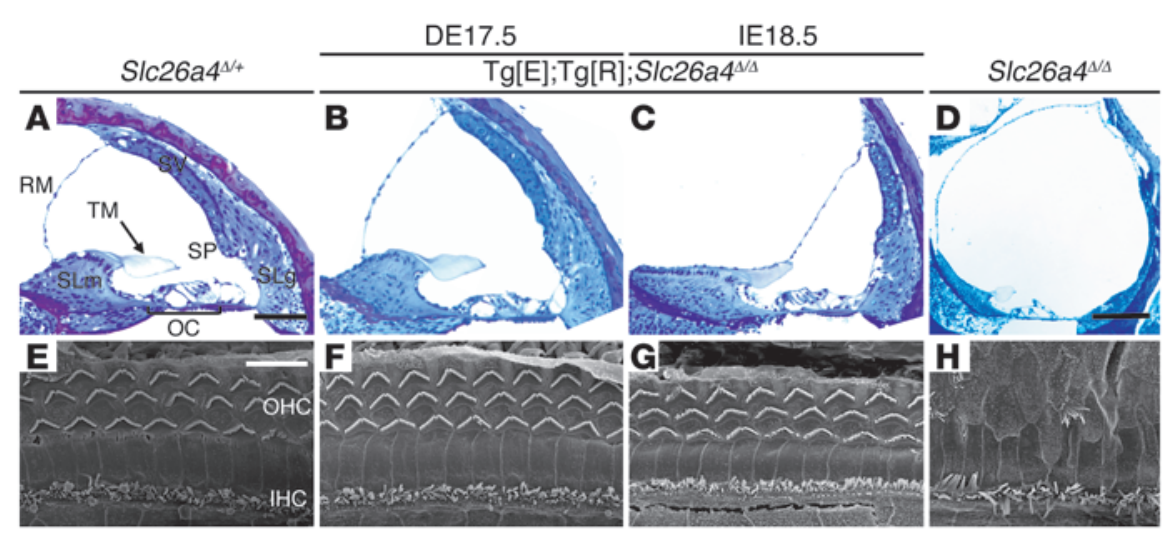

Morphology of the cochlear duct and organ of Corti at P25 to P35. (A-D) Light microscopic images of plastic-embedded sections of the middle cochlear turn stained with toluidine blue. $(\mathrm{E}-\mathrm{H})$ Scanning electron micrographs of the organ of Corti from the middle cochlear turn. Scale bars: $100 \mu \mathrm{m}$ (A, applies to A-C); $200 \mu \mathrm{m}$ (D); and $10 \mu \mathrm{m}$ (E, applies to $\mathbf{E}-\mathbf{H})$. Note the different scale bar in $\mathbf{D}$ for the enlarged cochlear duct of S/c26a4 ${ }^{\Delta / \Delta}$ mice. SLm, spiral limbus; TM, tectorial membrane; SLg, spiral ligament; OHC, 3 rows of outer hair cells; IHC, single row of inner hair cells. The Reissner membrane of $\mathrm{Tg}[\mathrm{E}] ; \mathrm{Tg}[\mathrm{R}] ; S / c 26 a 4^{\Delta / \Delta}$ IE18.5 ears is collapsed onto the spiral limbus and tectorial membrane. The spiral ganglion, stria vascularis, organ of Corti hair cells and other structures of the cochlear ducts of $\mathrm{Tg}[\mathrm{E}] ; \mathrm{Tg}[\mathrm{R}] ;$ Slc26a4 ${ }^{\Delta / \Delta} \mathrm{IE} 18.5$ and DE17.5 mice look similar to those of S/c26a4 $4^{\Delta+}$ controls. 

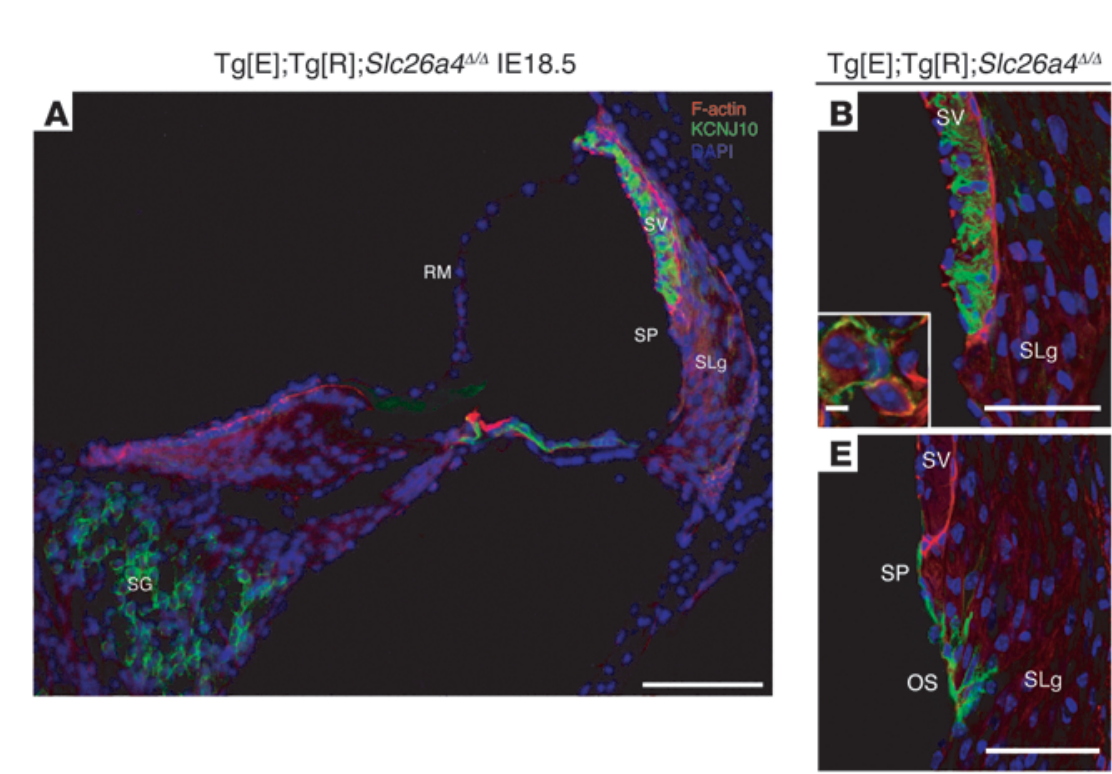

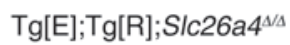
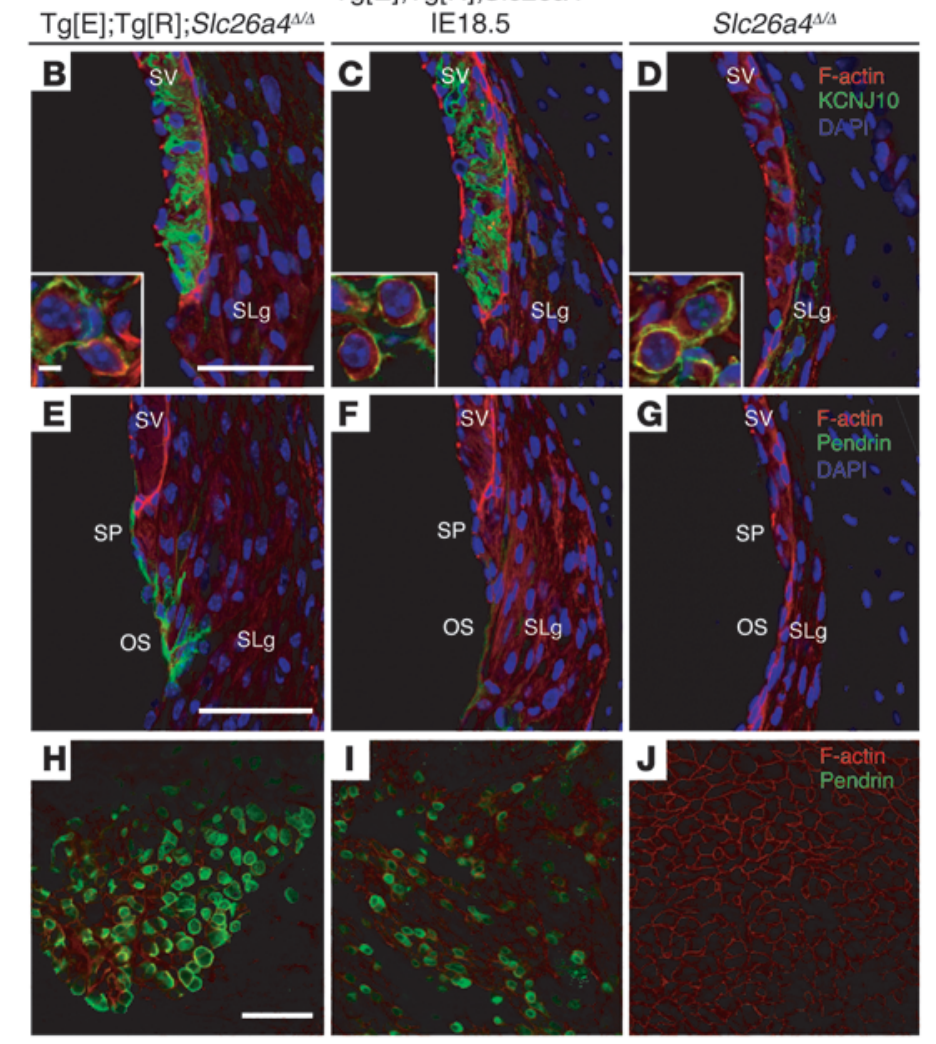

\section{Figure 8}

Kcnj10 and pendrin expression in the cochlea. (A-D) Anti-Kcnj10 or (E-J) anti-pendrin antibodies were used to immunostain Tg[E]; Tg[R];S/c26a4 $/ / \Delta$ IE18.5 (A, C, F, and I), Tg[E];Tg[R];S/c26a4 $4^{\Delta /+}(\mathbf{B}, \mathbf{E}$, and $\mathbf{H})$, or S/c26a4 ${ }^{\Delta / \Delta}(\mathbf{D}, \mathbf{G}$, and J) cochlea $(\mathbf{A}-\mathbf{G})$ or endolymphatic sac (H-J) at P27 to P34. Insets (B-D) show magnified views of the spiral ganglion (SG). Scale bars: $100 \mu \mathrm{m}$ (A); $50 \mu \mathrm{m}$ (B, applies to C-G); $5 \mu \mathrm{m}$ (inset in B, applies to insets in $\mathbf{C}$ and $\mathbf{D}) ; 50 \mu \mathrm{m}(\mathbf{H}$, applies to $\mathbf{I}$ and $\mathbf{J})$. Kcnj10 staining is evident in the intermediate layer of the stria vascularis as well as the spiral ganglion. Kcnj10 immunoreactivity in the lateral wall of $\mathrm{Tg}[\mathrm{E}] ; \mathrm{Tg}[\mathrm{R}] ; S / c 26 a 4^{\Delta / \Delta} \mathrm{IE} 18.5$ cochleae appears normal or slightly reduced. Pendrin immunoreactivity is reduced in the cochlea and endolymphatic sac of $\mathrm{Tg}[\mathrm{E}] ; \mathrm{Tg}[\mathrm{R}] ; \mathrm{S}_{\mathrm{c}} 26 \mathrm{a} 4^{\mathrm{\Delta} / \Delta} \mathrm{IE} 18.5 \mathrm{mice}$.

and the blocking solution was PBS with $2 \%$ bovine serum albumin and $5 \%$ normal goat serum. Primary antibodies were diluted 1:1000 (PB826) or 1:300 (anti-Kcnj10) in blocking solution, and the secondary antibody was Alexa Fluor 488-conjugated goat anti-rabbit IgG (\#A-11008; Invitrogen) diluted 1:500. Tissues were counterstained with rhodamine-phalloidin (Molecular Probes) at a 1:100 dilution. Slides were mounted with ProLong Gold antifade reagent (Invitrogen). Images were captured with an LSM780 confocal microscope equipped with ZEN 2010 software (Carl Zeiss).

$A B R$ analysis. ABR thresholds were measured essentially as described (33). Mice were anesthetized with a mixture of dexmedetomidine (Dexdomitor; $0.375 \mathrm{mg} / \mathrm{kg}$ body weight) and ketamine ( $56 \mathrm{mg} / \mathrm{kg}$ body weight). Mice were placed on a heating pad in a sound booth for testing with Opti-amp 8002 and IHSPROG-Smart EP software (Intelligent Hearing Systems). Responses were recorded to click, $8-\mathrm{kHz}, 16-\mathrm{kHz}$, or $32-\mathrm{kHz}$ pure-tone stimuli starting at $120 \mathrm{~dB}$ SPL and decreasing in $10-\mathrm{dB}$ steps until a hearing threshold was determined.

Paint-fill analysis. To visualize inner ear morphology, we injected methyl salicylate with latex paint into the membranous inner ears of embryonic and early postnatal mice as described $(19,34)$. Inner ears were partially injected at P3 to visualize the cochlear duct, saccule, endolymphatic sac, and duct regions (35).

Histopathology. Mice were euthanized by $\mathrm{CO}_{2}$ exposure followed by cervical dislocation. Inner ears were dissected and processed as described (36) using the ImmunoBed Kit (Polysciences Inc.) and a Leica RM2265 microtome.
Sections of $5-\mu \mathrm{m}$ thickness were stained with $1 \%$ toluidine blue. We captured images with ACT-1 software and a Nikon Digital Cam DXM1200 attached to a Nikon Eclipse 90i light microscope.

Measurement of vestibular aqueduct. Mice were deeply anesthetized with tribromoethanol and euthanized by transcardial perfusion with PBS (6 ml, $1 \mathrm{~min})$ followed by PBS with $4 \%$ paraformaldehyde ( $24 \mathrm{ml}, 4 \mathrm{~min}$ ). PBS contained $137 \mathrm{mM} \mathrm{NaCl}, 10.1 \mathrm{mM} \mathrm{Na}_{2} \mathrm{HPO}_{4}, 1.8 \mathrm{mM} \mathrm{KH}_{2} \mathrm{PO}_{4}$, and $2.7 \mathrm{mM} \mathrm{KCl}$, $\mathrm{pH}$ 7.4. Temporal bones were isolated and further fixed by perilymphatic perfusion via the oval and round windows ( $48 \mu \mathrm{l}$ via each window, 5 minutes) followed by 4-6 hours of agitation in PBS containing 4\% paraformaldehyde. Temporal bones were then washed and decalcified for 24 hours in PBS containing 10\% EDTA, processed through a sucrose gradient, and infiltrated with polyethylene glycol. Cryosections perpendicular to the axis of the endolymphatic duct were prepared (12 $\mu \mathrm{m}, \mathrm{CM} 3050 \mathrm{~S}$; Leica), washed, and stained for 30 seconds with $0.1 \%$ toluidine blue in PBS. Laser scans obtained with a red $(543 \mathrm{~nm})$, green $(488 \mathrm{~nm})$, and blue (402 nm) laser were overlaid to generate color images (LSM 510 Meta; Carl Zeiss). Cross-sectional areas of the vestibular aqueduct that contains the endolymphatic sac were measured using morphometry software provided by the manufacturer (Carl Zeiss). Color images were converted to black and white, and overlays were generated in CorelDRAW. Images without overlays are shown in Supplemental Figure 1. Electrochemical analysis of endolymph. Mice were anesthetized with tribromoethanol, and measurement of the perilymphatic $\mathrm{pH}$, the endolymphatic $\mathrm{pH}$, 
and the transepithelial potential were made using double-barreled microelectrodes. Procedures were developed by modifying previously described protocols $(13,37)$. Measurements were made in the basal turn of the cochlea by a round-window approach through the basilar membrane of the first turn. After placing electrodes in perilymph, the surgical cavity was covered with liquid Sylgard 184 (Dow Corning Corp.). This maneuver was designed to prevent the measurement of artificially elevated perilymphatic $\mathrm{pH}$ values due to the loss of tissue $\mathrm{CO}_{2}$ into ambient air. Data were recorded digitally (DIGIDATA 1322A and AxoScope 9; Axon Instruments) and analyzed using custom software written by P. Wangemann in LabTalk (Origin 6.0; The Origin Company). Calibration consisted of taking a reference value and obtaining the slope of the electrode in situ at $37^{\circ} \mathrm{C}$. This method was devised to minimize the contribution of electrode drift and differences between reference electrodes. $\mathrm{pH}$-sensitive electrodes had a slope of $56.7 \pm 0.4 \mathrm{mV} / \mathrm{pH}$ unit $(n=43)$. Three calibration solutions with different $\mathrm{pH}$ values were used. Calibration solution contained pH 6: $130 \mathrm{mM} \mathrm{NaCl}, 20 \mathrm{mM} \mathrm{MES}$; pH 7: $130 \mathrm{mM}$ $\mathrm{NaCl}, 20 \mathrm{mM}$ HEPES; and pH 8: $130 \mathrm{mM} \mathrm{NaCl}, 20 \mathrm{mM}$ tricine.

Double-barreled glass microelectrodes were manufactured from filament-containing glass tubing (1B100F-4; World Precision Instruments) using a micropipette puller (PD-5; Narishige). Prior to silanization, microelectrodes were baked at $180^{\circ} \mathrm{C}$ for 2 hours to ensure dryness. The longer ion-selective barrel was mounted in the lid of a beaker. The beaker was heated to $210^{\circ} \mathrm{C}$ and silanized by a 90 -second exposure to $0.02 \mathrm{ml}$ dimethyldichlorosilane (40136; Fluka) at room temperature. The shorter reference barrel was protected from silanization by sealing the open end with Parafilm (Alcan Packaging). After silanization, microelectrodes were baked at $180^{\circ} \mathrm{C}$ for 3 hours and tips were broken to a final OD of approximately $3 \mu \mathrm{m}$. The reference barrel was filled with $1 \mathrm{M} \mathrm{KCl}$, and the ion-selective barrel was filled at the tip with liquid ion exchanger (Hydrogen ionophore II Cocktail A, 95297; Fluka) and back-filled with buffer solution $(500 \mathrm{mM}$ $\mathrm{KCl}, 20$ mM HEPES, pH 7.4) (13, 37).

Statistics. A 2-tailed Mann-Whitney $U$ test, with a significance criterion of $P<0.05$, was used to compare the thickness of the stria vascularis.

Study approval. All animal experiments and procedures were performed according to protocols approved by the Animal Care and Use Committees of the National Institute of Neurological Diseases and Stroke/National Institute on Deafness and Other Communication Disorders and by the Animal Care and Use Committee at Kansas State University.

\section{Acknowledgments}

We thank Yoshiyuki Kawashima, Shin-ichiro Kitajiri, and Harold Neely for technical advice; Parna Chattaraj, Ya-Xian Wang, and NIDCD animal care staff for technical support; Doris Wu and Matthew Kelley for comments on the manuscript; and NIDCD colleagues for helpful discussions. This work was supported by NIH intramural research funds DC-000060-10 (to A.J. Griffith), DC-000039-14 (to T.B. Friedman) and DC-000003-23 (R.S. Petralia), CVM-SMILE from Kansas State University (to P. Wangemann), and NIH extramural fund P20-RR017686. Y. Wen was a Howard Hughes Medical Institute/NIH Research Scholar.

Received for publication June 6, 2011, and accepted in revised form August 10, 2011.

Address correspondence to: Andrew J. Griffith, Otolaryngology Branch, National Institute on Deafness and Other Communication Disorders, NIH, 5 Research Court, Room 2B-29, Rockville, Maryland 20850-3320, USA. Phone: 301.402.2829; Fax: 301.402.7580; E-mail: griffita@nidcd.nih.gov.

Byung Yoon Choi's present address is: Department of Otorhinolaryngology-Head and Neck Surgery, Seoul National University Bundang Hospital, Seoul National University College of Medicine, Seongnam, Korea.

Hyoung-Mi Kim's present address is: Department of Otolaryngology, CHA Bundang Medical Center, CHA University, Seongnam, Korea.

Kyu-Yup Lee's present address is: Department of Otolaryngology-Head and Neck Surgery, College of Medicine, Kyungpook National University, Daegu, Korea.

Kelly Monahan's present address is: University of Iowa Carver College of Medicine, Iowa City, Iowa, USA.

Yaqing Wen's present address is: Duke University School of Medicine, Durham, North Carolina, USA.
1. Valvassori GE, Clemis JD. The large vestibular aqueduct syndrome. Laryngoscope. 1978;88(5):723-728.

2. Phelps PD, et al. Radiological malformations of the ear in Pendred syndrome. Clin Radiol. 1998; 53(4):268-273

3. Griffith AJ, et al. Familial large vestibular aqueduct syndrome. Laryngoscope. 1996;106(8):960-965.

4. King KA, et al. SLC26A4 genotype, but not cochlear radiologic structure, is correlated with hearing loss in ears with an enlarged vestibular aqueduct. Laryngoscope. 2010;120(2):384-389.

5. Pendred V. Deaf-Mutism and goitre. Lancet. 1896; 2(3808):532.

6. Everett LA, et al. Pendred syndrome is caused by mutations in a putative sulphate transporter gene (PDS). Nat Genet. 1997;17(4):411-422.

7. Li XC, et al. A mutation in PDS causes nonsyndromic recessive deafness. Nat Genet. 1998; 18(3):215-217.

8. Campbell C, et al. Pendred syndrome, DFNB4, and PDS/SLC26A4 identification of eight novel mutations and possible genotype-phenotype correlations. Hum Mutat. 2001;17(5):403-411.

9. Choi BY, et al. Hypo-functional SLC26A4 variants associated with nonsyndromic hearing loss and enlargement of the vestibular aqueduct: genotypephenotype correlation or coincidental polymor- phisms? Hum Mutat. 2009;30(4):599-608.

10. Pryor SP, et al. SLC26A4/PDS genotype-phenotype correlation in hearing loss with enlargement of the vestibular aqueduct (EVA): evidence that Pendred syndrome and non-syndromic EVA are distinct clinical and genetic entities. J Med Genet. 2005;42(2):159-165.

11. Usami S, Abe S, Weston MD, Shinkawa H, Van Camp G, Kimberling WJ. Non-syndromic hearing loss associated with enlarged vestibular aqueduct is caused by PDS mutations. Hum Genet. 1999; 104(2):188-192.

12. Reardon W, CF OM, Trembath R, Jan H, Phelps PD. Enlarged vestibular aqueduct: a radiological marker of pendred syndrome, and mutation of the PDS gene. QJM. 2000;93(2):99-104.

13. Wangemann $\mathrm{P}$, et al. Loss of cochlear HCO3- secretion causes deafness via endolymphatic acidification and inhibition of $\mathrm{Ca} 2+$ reabsorption in a Pendred syndrome mouse model. Am J Physiol Renal Physiol. 2007;292(5):F1345-F1353.

14. Dou $\mathrm{H}$, et al. Co-expression of pendrin, vacuolar $\mathrm{H}+$-ATPase alpha4-subunit and carbonic anhydrase II in epithelial cells of the murine endolymphatic sac. J Histochem Cytochem. 2004;52(10):1377-1384.

15. Royaux IE, et al. Localization and functional studies of pendrin in the mouse inner ear provide insight about the etiology of deafness in pendred syndrome. J Assoc Res Otolaryngol. 2003;4(3):394-404.

16. Wangemann $\mathrm{P}$, et al. Loss of KCNJ10 protein expression abolishes endocochlear potential and causes deafness in Pendred syndrome mouse model. BMC Med. 2004;2:30.

17. Richardson GP, de Monvel JB, Petit C. How the genetics of deafness illuminates auditory physiology. Annu Rev Physiol. 2011;73:311-334.

18. Kim HM, Wangemann P. Epithelial cell stretching and luminal acidification lead to a retarded development of stria vascularis and deafness in mice lacking pendrin. PLoS One. 2011;6(3):e17949.

19. Everett LA, et al. Targeted disruption of mouse Pds provides insight about the inner-ear defects encountered in Pendred syndrome. Hum Mol Genet. 2001;10(2):153-161.

20. Kim HM, Wangemann P. Failure of fluid absorption in the endolymphatic sac initiates cochlear enlargement that leads to deafness in mice lacking pendrin expression. PLoS One. 2010;5(11):e14041.

21. Saunders TL. Inducible transgenic mouse models. Methods Mol Biol. 2011;693:103-115.

22. Meyers JR, et al. Lighting up the senses: FM1-43 loading of sensory cells through nonselective ion channels. J Neurosci. 2003;23(10):4054-4065.

23. Singh R, Wangemann P. Free radical stress-medi- 
ated loss of Kcnj10 protein expression in stria vascularis contributes to deafness in Pendred syndrome mouse model. Am J Physiol Renal Physiol. 2008;294(1):F139-F148.

24. Griffith AJ, Wangemann P. Hearing loss associated with enlargement of the vestibular aqueduct: Mechanistic insights from clinical phenotypes, genotypes, and mouse models [published online ahead of print June 6, 2011]. Hear Res. doi:10.1016/ j.heares.2011.05.009.

25. Scott DA, Wang R, Kreman TM, Sheffield VC, Karniski LP. The Pendred syndrome gene encodes a chloride-iodide transport protein. Nat Genet. 1999; 21(4):440-443.

26. $\mathrm{Ng} \mathrm{L}$, et al. A protective role for type 3 deiodinase, a thyroid hormone-inactivating enzyme, in cochlear development and auditory function. Endocrinology. 2009;150(4):1952-1960.

27. Wangemann P, et al. Developmental delays consis- tent with cochlear hypothyroidism contribute to failure to develop hearing in mice lacking Slc26a4/ pendrin expression. Am J Physiol Renal Physiol. 2009; 297(5):F1435-F1447.

28. Pech V, et al. Pendrin modulates ENaC function by changing luminal HCO3. J Am Soc Nephrol. 2010; 21(11):1928-1941.

29. Gow A, et al. Deafness in Claudin 11-null mice reveals the critical contribution of basal cell tight junctions to stria vascularis function. J Neurosci. 2004; 24(32):7051-7062.

30. Ikeya M, et al. Gene disruption/knock-in analysis of mONT3: vector construction by employing both in vivo and in vitro recombinations. Int J Dev Biol. 2005;49(7):807-823.

31. Wang J, et al. An improved recombineering approach by adding RecA to lambda Red recombination. Mol Biotechnol. 2006;32(1):43-53.

32. Kozak M. Compilation and analysis of sequences upstream from the translational start site in eukaryotic mRNAs. Nucleic Acids Res. 1984;12(2):857-872.

33. Noguchi Y, et al. Multiple quantitative trait loci modify cochlear hair cell degeneration in the Beethoven (Tmc1Bth) mouse model of progressive hearing loss DFNA36. Genetics. 2006;173(4):2111-2119.

34. Morsli H, Choo D, Ryan A, Johnson R, Wu DK. Development of the mouse inner ear and origin of its sensory organs. J Neurosci. 1998;18(9):3327-3335.

35. Cantos R, Cole LK, Acampora D, Simeone A, Wu DK. Patterning of the mammalian cochlea. Proc Natl Acad Sci U S A. 2000;97(22):11707-11713.

36. Noben-Trauth K, Latoche JR, Neely HR, Bennett B. Phenotype and genetics of progressive sensorineural hearing loss (Snhl1) in the LXS set of recombinant inbred strains of mice. PLoS One. 2010;5(7):e11459.

37. Marcus DC, Rokugo M, Thalmann R. Effects of barium and ion substitutions in artificial blood on endocochlear potential. Hear Res. 1985;17(1):79-86. 